\section{Allergy Immunology}

\title{
Associate Editor Thilo Jakob
}

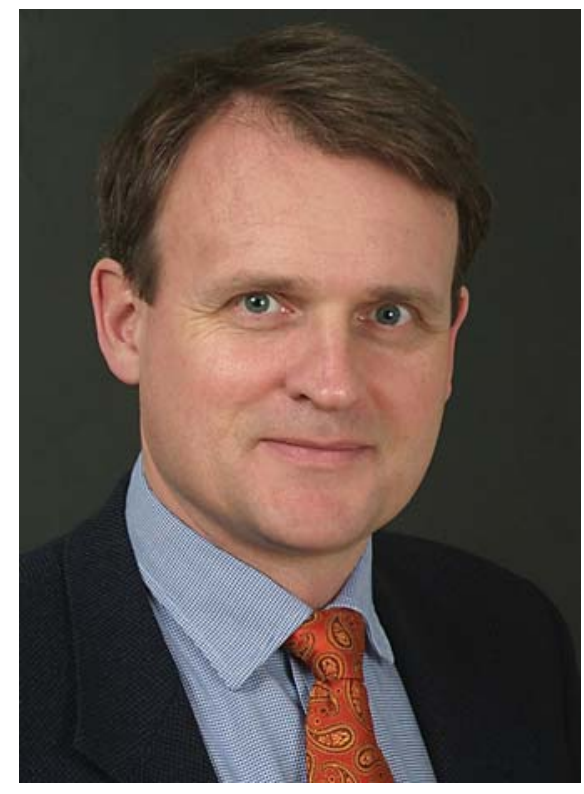

Thilo Jakob, Freiburg.
Thilo Jakob, MD, is Professor of Allergy and Immunodermatology. He is Chair of the Allergy Research Group and Deputy Chairman of the Department of Dermatology at the University Medical Center Freiburg, Germany. After his undergraduate training in Medicine at the Ludwig Maximilian University Munich and in Immunology at the University College London with Prof. Ivan Roitt, he started his residency in dermatology and earned his doctoral degree at the University of Hamburg. For his postdoctoral training, he joined the group of Dr. Mark Udey in the Dermatology Branch of the National Cancer Institute, NIH, Bethesda, Md. He finished his residency in the dermatology and allergy program at the Technical University of Munich with Prof. Johannes Ring before he took his first faculty position at the ZAUM Center for Allergy and Environmental Dermatology, Munich, with Prof. Heidrun Behrendt. Since 2006, he holds a full professorship in allergy and immunodermatology at the University Medical Center of the Albert Ludwig University in Freiburg.

Prof. Jakob has been a board member of the German Society for Allergy and Clinical Immunology since 2009, served on the Executive Board of the European Academy of Allergy and Clinical Immunology from 2005 to 2009 and is a member/fellow of many academic organizations, including the Collegium Internationale Allergologicum.

His research is focused on mechanisms of tolerance induction and the role of the innate immune response in sensitization and elicitation of allergic reactions. He works on disease models of allergic asthma and allergic contact dermatitis. In addition, he is interested in the translational aspect of modern molecular allergology and its applications in the daily clinical routine, with a focus on improved methods for allergy diagnostics in insect venom allergy. He has published more than 140 articles as peer-reviewed original articles, invited reviews and book chapters. Since 2010, he has been the Editor of the Allergo Journal - Interdisciplinary Journal for Allergy, Clinical Immunology and Environmental Medicine, the official journal of the German Society for Allergic and Clinical Immunology. Furthermore, he serves a number of editorial boards in the fields of allergy and clinical immunology. 